\title{
Cellular mechanisms regulating sperm-zona pellucida interaction
}

\author{
Andrew T Reid ${ }^{1}$, Kate Redgrove ${ }^{1}, \mathrm{R}$ John Aitken $^{1,2}$ and Brett Nixon ${ }^{1}$
}

For mammalian spermatozoa to exhibit the ability to bind the zona pellucida (ZP) they must undergo three distinct phases of maturation, namely, spermatogenesis (testis), epididymal maturation (epididymis) and capacitation (female reproductive tract). An impressive array of spermatozoa surface remodeling events accompany these phases of maturation and appear critical for recognition and adhesion of the outer vestments of the oocyte, a structure known as the ZP. It is becoming increasingly apparent that species-specific zona adhesion is not mediated by a single receptor. Instead, compelling evidence now points toward models implicating a multiplicity of receptor-ligand interactions. This notion is in keeping with emerging research that has shown that there is a dynamic aggregation of proteins believed to be important in sperm-ZP recognition to the regions of sperm that mediate this binding event. Such remodeling may in turn facilitate the assembly of a multimeric zona recognition complex (MZRC). Though formation of MZRCs raises questions regarding the nature of the block to polyspermy, formation and assembly of such a structure would no doubt explain the strenuous maturation process that sperm endure on their sojourn to functional maturity.

Asian Journal of Andrology (2011) 13, 88-96; doi:10.1038/aja.2010.74; published online 1 November 2010

Keywords: capacitation; fertilization; spermatozoa; sperm-zona pellucida interaction

\section{INTRODUCTION}

Defining the molecular mechanisms that underlie the species-specific interaction(s) between a fertilizing spermatozoon and the zona pellucida (ZP) has been a challenge that after more than 30 years of solid investigation has still not been overcome. ${ }^{1-4}$ Gaining a thorough understanding of these mechanisms would aid in tackling the dual problems of explosive population growth in developing countries, and the increasing incidence of infertility throughout many developed countries.

The world population is estimated to reach seven billion by early 2012. ${ }^{5}$ Alarmingly, the majority of this population growth is occurring in developing countries where it is being driven, in part, by an unmet need for family-planning resources. Indeed, a recent analysis by the Global Health Council has indicated that of the 205 million worldwide pregnancies per year, as many as $30-40 \%$, are unplanned. ${ }^{6}$ These statistics relay the inadequacy of current contraceptive measures and thus highlight the need for new approaches to contraception. By virtue of its specificity and susceptibility to suppression in both males and females, sperm-ZP interaction represents an attractive target for contraceptive development. The realization of such technology is, however, predicated on our ability to gain a comprehensive understanding of the mechanisms that underpin this fundamental interaction. Such knowledge would have the added benefit of helping to elucidate the reasons behind the paradoxical increase in the incidence of unexplained male factor infertility in developed nations. Reliable estimates suggest that as many as $17 \%$ of the couples in these countries currently take recourse to assisted reproductive technologies in an attempt to counter the problem of infertility. ${ }^{7}$ Furthermore, in $\sim 40 \%$ of these cases, a specific, but generally poorly defined, male factor is believed to be the underlying cause. ${ }^{8}$

This review explores our current understanding of the mechanisms that underpin sperm-ZP interaction. Consideration is given to wellestablished paradigms of receptor-ligand interactions with an emphasis on emerging evidence for models involving the participation of multimeric receptor complexes and the maturational events that promote their assembly.

\section{MATURATION OF MAMMALIAN SPERMATOZOA}

Spermatogenesis

To gain the functional competence to bind the $\mathrm{ZP}$ of an ovulated oocyte, spermatozoa must first undergo three distinct phases of maturation, namely, spermatogenesis, epididymal maturation and capacitation (Figure 1). Spermatogenesis is an intricate, exceptionally complex process that occurs in the male testis and is responsible for the production of large numbers of spermatozoa. During this process, spermatids undergo a dramatic morphological transformation from a rounded shape into an elongated cell consisting of a number of unique highly specialized regions: a head comprising the acrosomal vesicle, nucleus, cytoskeletal structures and cytoplasm; a midpiece which houses the mitochondria; and a flagellum that is used for locomotion. The majority of these changes occur during the final phase of cytodif- 

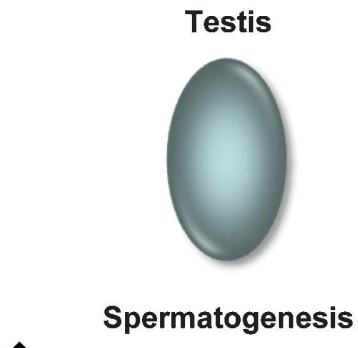

Epididymis

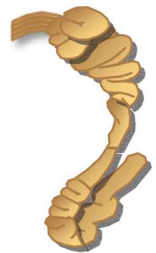

Female Reproductive Tract

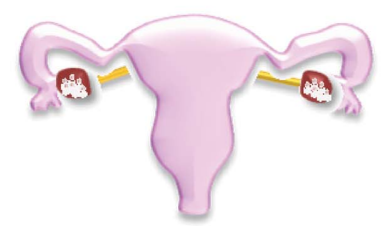

Capacitation

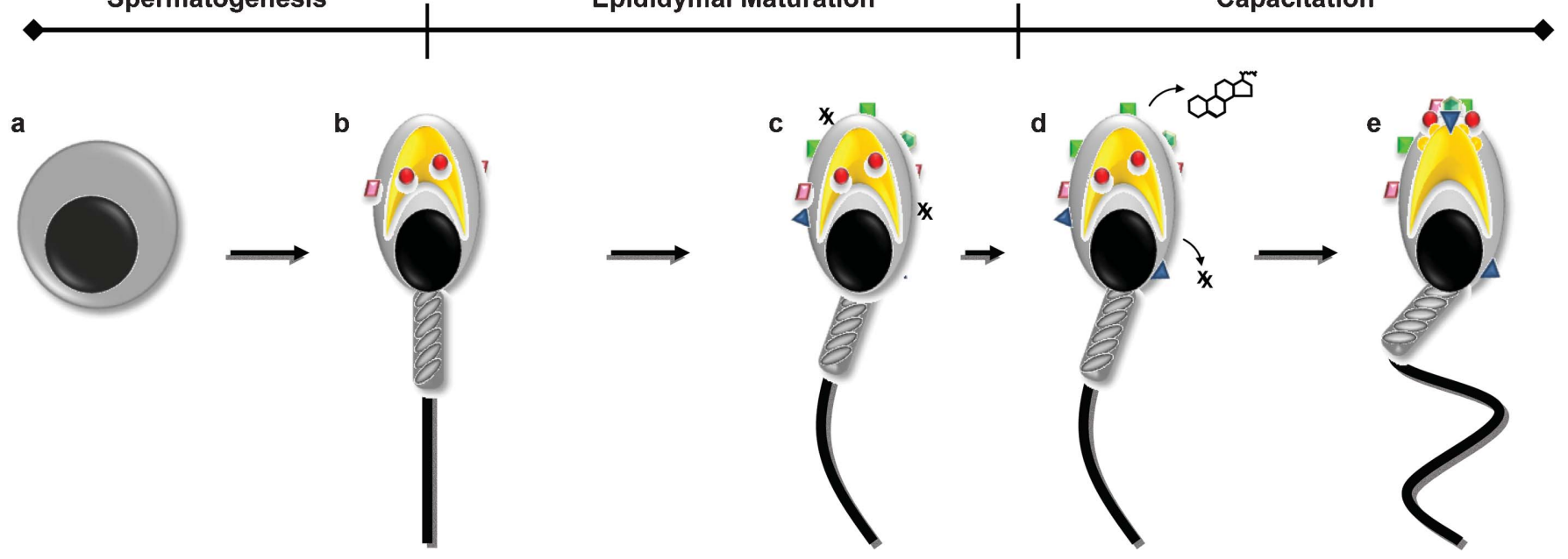

Figure 1 Schematic representing the distinct changes in sperm surface architecture throughout the three stages of sperm maturation. Spermatogenesis, occurring in the testis, comprises the sequence of cell divisions and immense morphological alterations that convert the round spermatogonia (a) into large numbers of morphologically mature spermatozoa (b). Incorporated in this maturation process is the intrinsic expression of a number of proteins believed to participate in sperm-ZP interaction. Following spermatogenesis, spermatozoa then undergo a second phase of maturation, namely, 'epididymal maturation' in which spermatozoa are bathed in a complex intraluminal milieu that appears to imbue the cells with a large number of proteins/molecules that are also necessary for successful fertilization (c). An additional modification is the uptake of DFs (X) that prevent the cells from undergoing premature capacitation. The final phase of sperm maturation, capacitation, occurs within the female reproductive tract and culminates in the acquisition of full functional competence. Two distinct events occur during the initial stages of capacitation, namely, cholesterol efflux, and removal of DFs (d). Following the loss of these inhibitory molecules, complex signaling pathways are activated that result in both the attainment of hyperactivated motility and ability to bind the ZP. Distinct membrane remodeling events accompany this process including phospholipid scrambling and a dynamic coalescence of lipid rafts and putative receptor molecules to sites on the apical margin of the sperm surface that are capable of ZP interaction (e). This process may also be augmented by the translocation of proteins, such as ZP3R, from within the acrosomal matrix to the sperm plasma membrane. Such events are likely facilitated via budding of the outer acrosomal membrane resulting in formation of fusion pores. Upon aggregation of receptor molecules, the assembly of MZRCs is predicted to occur through the concerted action of a subset of molecular chaperones, thus producing cells that exhibit the functional competence required for adhesion to the ZP. DF, decapacitation factor; MZRC, multimeric zona recognition complex; ZP, zona pellucida; ZP3R, ZP3 receptor.

ferentiation, spermiogenesis, and are accompanied by protamine packaging of the DNA. Significantly, this latter event also results in silencing of the sperm's transcriptional machinery ${ }^{9-13}$.

\section{Epididymal maturation}

Although spermatozoa that leave the testes are morphologically mature, they are still functionally incompetent, lacking both the capacity for forward progressive motility and the ability to bind the $\mathrm{ZP}^{14}$. These attributes are progressively acquired as the cells traverse the highly convoluted male reproductive tract or epididymis. The epididymis is a single duct that is generally subdivided into three broad anatomical regions: the caput (head) region, an adjoining corpus (body) region and the cauda (tail) region that terminates in the vas deferens. As mammalian spermatozoa progress from caput to cauda, they undergo distinct morphological refinement together with a series of biochemical alterations, ultimately producing cells that harbor both the potential for forward progressive motility and capacity for fertilization. ${ }^{15-18}$ In most mammalian species, the potential to bind the ZP is first exhibited in the proximal corpus region, before reaching maximal levels in spermatozoa from the cauda region. ${ }^{18-20}$

One remarkable feature of this functional transformation is that it is not intrinsically driven. Indeed, owing to the exceptionally compact state of the spermatozoon genome, transcription is silenced and the balance of evidence suggests that the cells also remain translationally quiescent throughout their post-testicular maturation. ${ }^{21}$ Modifications to sperm architecture therefore appear to be stimulated by the complex intraluminal milieu in which the spermatozoa are bathed as they pass through the epididymal tubule. ${ }^{22}$ Among the more overt changes accompanying this period of maturation are remodeling of the sperm plasma membrane through the exchange and/or modification of a myriad of key lipids and proteins. ${ }^{23-26}$ Although the molecular basis of these events and their contribution to the acquisition of ZP-binding affinity remain to be fully elucidated, they are temporally correlated with the appearance of two distinct subsets of macromolecular structures within the epididymal lumen: membrane-bound, prostasomelike epididymosomes ${ }^{27-29}$ and molecular chaperone-laden 'dense bodies'. ${ }^{30}$ Emerging evidence suggests that these entities juxtapose with the sperm plasma membrane and potentiate the bulk transfer of proteins, including a subset implicated in sperm-oocyte interactions, to the sperm surface. ${ }^{31,32}$

\section{Capacitation}

Notwithstanding the functional transformation of spermatozoa that accompanies epididymal maturation, the cells do not realize their full 
potential for fertilization until after ejaculation whereupon they undergo a final stage of maturation termed 'capacitation'. ${ }^{33-35}$ Capacitation is stimulated as the cells ascend the female reproductive tract and is characterized by distinct biochemical and biophysical changes that act to modify the sperm surface, alter the intracellular $\mathrm{pH}$ and stimulate a number of integrated signal transduction pathways. ${ }^{36-38}$ A key correlate of the latter events is the dramatic upregulation of tyrosine phosphorylation across a large number of target proteins. This has in turn been causally linked to the attainment of a hyperactivated pattern of motility, recognition and adhesion of the $\mathrm{ZP}$, and the ability to undergo acrosomal exocytosis (reviewed by Ref. 39).

For the purpose of this review, focus will be placed on the mechanisms that culminate in the ability of sperm to engage in interaction with the ZP (Table 1). Furthermore, as this is a cell surface-mediated event, discussion will be centered upon the capacitation-associated pathways that mediate sperm surface remodeling. One of the most well-documented events in this regard is a substantial efflux of cholesterol from the sperm plasma membrane that occurs during the initial stages of sperm capacitation. ${ }^{40}$ This efflux appears to be driven by active sequestration upon exposure to cholesterol sinks ${ }^{41-43}$ and is therefore reasoned to produce a more permeable plasma membrane in which the lateral movement of integral membrane proteins can occur more readily. ${ }^{44}$ Bovine serum albumin is commonly used within in vitro capacitating media to act as a cholesterol acceptor although an analogous acceptor is believed to be present within the female reproductive tract. Indeed, studies utilizing tritiated thymidine sterols and human follicular fluid indicate the high-binding efficiency of follicular fluid albumin for cholesterol. ${ }^{42}$

At present, it remains unclear whether this large cholesterol efflux precedes or acts in concert with changes induced by the bicarbonate ion $\left(\mathrm{HCO}_{3}^{-}\right){ }^{45-48}$ In addition to its vital role in the initiation of key signaling processes, $\mathrm{HCO}_{3}^{-}$has itself been shown to have a more direct role in sperm surface remodeling via stimulation of phospholipid scrambling. ${ }^{49,50}$ Such scrambling destroys the characteristic membrane asymmetry, as distinct phospholipids are randomly 'flipflopped' across the bilayer. This redistribution of phospholipids has been theorized to be a prerequisite for cholesterol efflux, ${ }^{51}$ thus rendering the sperm membrane fusogenic and responsive to ZP glycoproteins. $^{52}$

Cholesterol efflux may also be preceded by loss of inhibitory molecules, known as decapacitation factors (DFs), from the sperm surface.

Table 1 Specific biochemical-and molecular-based changes that occur within mammalian spermatozoa during capacitation and underpin the acquisition of the ability to engage in sperm-egg interactions

\begin{tabular}{|c|c|c|}
\hline Phenomenon & Example & References \\
\hline Loss of DFs & $\begin{array}{l}\text { A 40-kDa glycoprotein (termed decapacitation factor) first characterized by Fraser and colleagues, binds a GPI-anchored membrane } \\
\text { receptor and is believed to upregulate the activity of a membrane-bound } \mathrm{Ca}^{2+} \text {-ATPase within uncapacitated murine spermatozoa. As } \\
\text { capacitation commences, a loss of DFs immediately ensues resulting in cessation of its regulatory role in } \mathrm{Ca}^{2+} \text {-ATPase, thus intracellular } \\
\mathrm{Ca}^{2+} \text { levels rise stimulating further events involved in capacitation. Interestingly, the DF has also been postulated to be able to reverse the } \\
\text { capacitation of mouse spermatozoa }\end{array}$ & $\begin{array}{c}53,55,154, \\
155\end{array}$ \\
\hline Cholesterol efflux & $\begin{array}{l}\text { Upon initiation of capacitation within the female reproductive tract, spermatozoa experience a dramatic loss of cholesterol. This process is } \\
\text { initiated by exposure to cholesterol sinks, such as albumin, which are present within uterine fluid. The loss of cholesterol leads to the } \\
\text { activation of transmembrane signaling pathways that involve PKA and culminate in protein tyrosine phosphorylation. Cholesterol efflux also } \\
\text { promotes an increase in membrane fluidity, providing an amorphous platform for the lateral movement of integral membrane proteins }\end{array}$ & $\begin{array}{l}40,42,44 \\
156\end{array}$ \\
\hline Lipid scrambling & $\begin{array}{l}\text { Parallel with cholesterol efflux is the well-documented influx of bicarbonate ion }\left(\mathrm{HCO}_{3}^{-}\right) \text {. In addition to the initiation of complex signaling } \\
\text { pathways (see below), this ion has been demonstrated to disrupt sperm plasma membrane asymmetry. The latter event appears causally } \\
\text { linked to the activation of phospholipid scramblases that drive the randomization of the phospholipid architecture in the spermatozoon } \\
\text { plasma membrane. The resultant effect is a destabilization of the sperm plasma membrane that in turn renders it more fusogenic }\end{array}$ & $49,52,157$ \\
\hline $\begin{array}{l}\text { Activation of signal } \\
\text { transduction } \\
\text { pathways }\end{array}$ & $\begin{array}{l}\text { An alternate role for } \mathrm{HCO}_{3}^{-} \text {is the stimulation of a sperm-specific soluble adenylyl cyclase, which in turn increases production of cAMP } \\
\text { resulting in activation of PKA and the subsequent tyrosine phosphorylation of a myriad of target proteins. This global increase in tyrosine } \\
\text { phosphorylation ultimately drives many of the important aspects of the capacitation process, such as the induction of hyperactivated } \\
\text { motility. It has also been speculated that cross-talk occurs between the PKA pathway and an alternate pathway that is stimulated through } \\
\text { the removal of DFs such as PEBP1. Specifically, PEBP1 is hypothesized to be a suppressor of Raf-1, an important part of the extracellular } \\
\text { signal-regulated kinase family of mitogen-activated protein kinases }\end{array}$ & $\begin{array}{l}36-38,158 \\
160\end{array}$ \\
\hline Lipid raft movement & $\begin{array}{l}\text { The plasma membranes of non-capacitated spermatozoa are thought to be composed of specific microdomains (lipid rafts) that } \\
\text { compartmentalize proteins/molecules for them to efficiently fulfill their functional roles. Upon capacitation, and subsequent to cholesterol } \\
\text { efflux, markers for these lipid rafts such as } \mathrm{G}_{\mathrm{M} 1} \text { ganglioside and flotillin, have been demonstrated to coalesce at sites within the apical } \\
\text { margin of the sperm head that are commensurate with those implicated in ZP recognition. These raft domains have been shown to } \\
\text { comprise a number of putative ZP receptor molecules (for example, GalT1, ZP3R and SPAM1). It is therefore hypothesized that raft } \\
\text { domains may act as platforms for the aggregation of proteins/molecules that are crucial for ZP binding }\end{array}$ & $144-146$ \\
\hline $\begin{array}{l}\text { Acquisition of ZP } \\
\text { binding ability }\end{array}$ & $\begin{array}{l}\text { During capacitation, spermatozoa acquire the ability to interact with the ZP. However, as these cells are transcriptionally silent this acquisition } \\
\text { of functional competence must be mediated by the remodeling, unmasking or post-translational modification of existing proteins. Interesting } \\
\text { examples of these phenomena include proteins such as ZP3R and several molecular chaperones that translocate from intracellular sites } \\
\text { (such as the acrosomal matrix) into lipid raft microdomains on the surface of mouse spermatozoa following capacitation }\end{array}$ & 119-121 \\
\hline $\begin{array}{l}\text { Acquisition of ability } \\
\text { of acrosome to } \\
\text { react }\end{array}$ & $\begin{array}{l}\text { Although there are many correlates associated with capacitation, the end point of this process is generally acknowledged as the ability to } \\
\text { undergo a stimulus induced acrosome reaction. Although it remains contentious, prevailing evidence indicates that this exocytotic event } \\
\text { is initiated by aggregation of sperm receptors by ZP3 ligands, which in turn induces a biphasic release of intracellular Ca }{ }^{2+} \text {. However, } \\
\text { more recent evidence suggests that sperm binding to the ZP is not completely sufficient for inducing acrosomal exocytosis, and that the } \\
\text { ZP may instead slow or stop the forward progressive motion of the sperm, and the subsequent thrusting of the tail transduces a } \\
\text { mechanosensory signal that leads to the mobilization of acrosomal calcium stores resulting in acrosomal exocytosis }\end{array}$ & 161,162 \\
\hline
\end{tabular}

Abbreviations: DF, decapacitation factor; GalT1, $\beta$-1,4-galactosyltransferase; GPI, glycosylphophatidylinositol; PEBP1, phosphatidylethanolamine-binding protein 1; PKA, protein kinase A; SPAM1, sperm adhesion molecule 1; ZP, zona pellucida; ZP3R, ZP3 receptor. 
These factors originate predominantly in the epididymis and accessory organs, and their removal from populations of non-capacitated spermatozoa results in a rapid increase in fertilizing ability. ${ }^{53} \mathrm{~A}$ range of DFs have been characterized in eutherian mammals such as HongrES $1,{ }^{54}$ DF glycoprotein ${ }^{55}$ and phosphatidylethanolamine-binding protein $1 .{ }^{56}$ Recently, an additional DF, NYD-SP27, has been identified in human spermatozoa that is not derived from epididymal secretions, but is instead intrinsic to the spermatozoa. ${ }^{57}$

A further modification that appears to be tied to capacitation-associated cholesterol efflux is a polarized coalescence of proteins and lipids that reside within specialized plasma membrane domains termed as 'lipid rafts'. Lipid rafts are generally defined as small, heterogeneous domains that serve to compartmentalize cellular processes, ${ }^{58}$ regulate the distribution of membrane proteins, and promote the activation of receptors and triggering of downstream signal cascades. ${ }^{59-62} \mathrm{~A}$ widely used method to isolate lipid rafts exploits the detergent-resistant nature of the 'raft' region, and thus these domains are often referred to as detergent resistant membranes. ${ }^{63}$ Lipid rafts will be discussed in more detail further in this review. What is important to note, however, is that the aggregation of these microdomains within the apical head region is believed to be very important for imbuing sperm with the ability to bind the glycoprotein ligands of the ZP.

\section{STRUCTURE, FUNCTION AND BIOCHEMISTRY OF THE ZP}

The ZP is a porous extracellular matrix that surrounds mammalian oocytes, ovulated eggs and embryos until the blastocyst stage of development. ${ }^{64-67}$ It is composed of a small number of glycoproteins that are held together via non-covalent bonds to form long, interconnected fibrils. In mice, the ZP comprises three major sulfated glycoproteins-designated mZP1 (200 kDa), mZP2 (120 kDa) and mZP3 $(83 \mathrm{kDa})$. In addition to orthologues of these three proteins (hZP1 (100 kDa), hZP2 (75 kDa) and hZP3 (55 kDa)), the human ZP comprises a fourth glycoprotein, hZP4 $(65 \mathrm{kDa}) ;{ }^{68,69}$ however, expression of the homologous protein in the mouse does not occur owing to a $Z p 4$ pseudogene being present. ${ }^{39,69,70}$ Current evidence suggests that the mouse $\mathrm{ZP}$ is a non-covalently assembled structure composed of ZP2-ZP3 dimers that polymerize into filaments crosslinked by $\mathrm{ZP} 1 .^{71,72}$ Furthermore, each of these $\mathrm{ZP}$ glycoproteins is heterogeneously glycosylated with asparagine-linked $\left(N_{-}\right)$and serine/threonine-linked $\left(\mathrm{O}_{-}\right)$oligosaccharides, which also display varying degrees of sialylation and sulfation.

The initial interaction between spermatozoa and the ZP is loose and relatively non-specific. ${ }^{73}$ It is, however, rapidly followed by a significantly tighter binding that is largely species-specific and mediated by complementary receptor/ligand molecules expressed on the surface of the spermatozoa and $\mathrm{ZP}$, respectively. Pioneering experiments performed by Bleil and Wassarman ${ }^{74-76}$ using crudely purified native $\mathrm{ZP}$ demonstrated that it is ZP3 that acts as both the primary sperm ligand, preferentially binding the plasma membrane overlying the acrosome of acrosome-intact sperm, and also acts as an acrosome reaction inducer during fertilization. For instance, purified mouse ZP3 competitively inhibits binding of mouse spermatozoa to mouse eggs in vitro. ${ }^{74,77}$ In contrast, both ZP1 and ZP2 lack this inhibitory activity. Instead, ZP2 appears to act as a secondary ligand that, by virtue of its ability to bind to the inner acrosomal membrane, is involved in securing the adhesion of acrosome-reacted sperm and subsequently triggers events that are important for the prevention of polyspermy. ${ }^{75,78}$ Such findings have since been validated by the generation of elegant transgenic models to study ZP function. These studies have provided overwhelming support for the importance of $\mathrm{ZP} 3$ in mediating primary sperm-oocyte interaction in the mouse. Indeed, female mice bearing a null mutation for ZP3 are completely infertile. ${ }^{79}$

Despite decades of investigation, the molecular basis of mammalian sperm-ZP3 recognition remains controversial. Prevailing evidence indicates that this interaction is most likely mediated by an intricate functional interplay between ZP3 carbohydrates and lectin-like proteins located on the sperm head. ${ }^{80,81}$ Indeed, a variety of monosaccharides, complex carbohydrate moieties and lectins have been shown to effectively block the tight binding of spermatozoa from a number of mammalian species (including human) to homologous ZP3. ${ }^{82-89}$ The most widely, although not universally, accepted model of primary sperm-ZP3 has been developed from studies of mouse models, and emphasizes the importance of $O$-linked carbohydrate moieties located near the carboxy terminus of the ZP3 glycoprotein. ${ }^{90-94}$ Evidence in support of this model has been advanced by the demonstration that complete deglycosylation or selective removal of $O$-linked oligosaccharides eliminates the ability of ZP3 to interact with spermatozoa. ${ }^{91}$ Furthermore, the $O$-linked oligosaccharides released by these procedures bind directly to spermatozoa and competitively inhibit their ability to adhere to the ZP. ${ }^{91}$ However, the bioactive components of the complex $\mathrm{O}$-linked oligosaccharide ligand(s) that furnish the ZP3 protein remain to be unequivocally established and are the subject of ongoing debate. ${ }^{95}$ This controversy has recently been intensified by the production of transgenic mice bearing single or multiple null mutations for key glycosyltransferases that generate many of the $\mathrm{O}$-glycans normally found in the zona. ${ }^{96-98}$ Remarkably, such mice produce oocytes that retain the ability to be fertilized. These results may therefore suggest a role for alternate carbohydrate moieties that furnish ZP glycoproteins in sperm recognition and binding. Indeed, murine ZP3 has been shown to exhibit high mannose and complex-type $N$ glycans. ${ }^{95}$ Further to this, it should be noted that not all mammalian species exhibit complete dependency on the $O$-linked oligosaccharides for sperm-ZP binding. For instance, in species such as the pig, there is evidence to suggest that $N$-linked neutral carbohydrate chains of the ZP3 orthologue appear to mediate its sperm receptor activity. ${ }^{99,100}$ Furthermore, current evidence has also suggested that $\mathrm{N}$-linked glycosylation of ZP3 may have a more significant role in human sperm$\mathrm{ZP}$ binding, compared with $\mathrm{O}$-linked glycosylation. ${ }^{101}$

Among the carbohydrate-independent sperm-ZP models that have been proposed, a small number of studies have suggested that this interaction may be facilitated, at least in part, by the core polypeptide backbone of ZP3. ${ }^{77,102,103}$ Notably, phenotypic analysis of a number of transgenic mouse models has also raised the prospect that the threedimensional structure of the zona matrix, rather than a single protein (or carbohydrate), may be central in mediating sperm binding. ${ }^{81,104,105}$ Furthermore, it has also been suggested that before interaction with ZP3 ligands, spermatozoa are tethered to the ovulated oocyte via adhesion to a distinct glycoform of the high molecular weight, oviduct-specific glycoprotein that coats the ZP and perivitelline space. ${ }^{106,107}$

\section{PRIMARY SPERM-ZP INTERACTION}

The original model of primary sperm-ZP adhesion portrayed a relatively simple, single receptor-ligand interaction. This in turn provided the impetus for fervent, large-scale searches for 'the' putative sperm receptor molecule. The ensuing research identified a range of molecules as potential instigators of this species-specific binding event and some of the more promising of these candidates will be briefly discussed here.

The ability of enzymes to elicit substrate-specific catalysis makes them ideal candidates for the initial binding between sperm and the 
ZP. A range of enzymes have been suggested, with the support of significant experimental evidence, to mediate this interaction. Owing to the large number of potential candidates, only a selected few will be briefly introduced. These include glycosyl enzymes, such as $\beta$-1,4-galactosyltransferase (GalT1), ${ }^{108-110}$ fucosyltransferase- $5^{111}$ and $\alpha$-D-mannosidase. ${ }^{112}$ For many years, GalT1 was favored as the most likely ZP3 receptor protein due in part to its ability to bind $\mathrm{N}$-acetylglucosamine residues on ZP3, although being present as an integral plasma membrane component expressed upon the anterior region of the sperm head. ${ }^{108,109}$ Interestingly, however, the generation of GalT1-null mice did not reveal the expected infertile phenotype but rather a subfertile one, ${ }^{113}$ thereby providing some of the first convincing evidence for functional redundancy among the putative $\mathrm{ZP}$ receptor candidates.

Lectins are a range of proteins that are defined as having a high affinity for specific carbohydrates; thus, they are also well placed for a potential role in mediating mammalian sperm-ZP binding. Indeed, a number of lectins and lectin-like proteins have been shown to be important for this binding, including rabbit sperm autoantigen, ${ }^{114}$ and the well-characterized ZP3R (formerly SP56). The ZP3R protein displays lectin-like affinity for galactose residues. ${ }^{115}$ Interestingly, galactose present at the non-reducing terminus of $O$-linked oligosaccharides, as well as ZP3R itself, has been demonstrated to have a role in sperm-zona binding in mouse. ${ }^{116,117}$ Recent characterization of the ZP3R protein has also offered an interesting insight into the underlying capacitation-associated priming mechanisms required for sperm-ZP interactions. ZP3R was originally identified on the basis of photoaffinity crosslinking studies as a primary receptor for ZP3. ${ }^{115,118}$ This role was subsequently discounted on the basis of ultrastructural evidence that revealed that the protein resided within the acrosomal matrix. ${ }^{119,120}$ As such a location is incompatible with the mediation of primary ZP3 binding, it was postulated that the ZP3R was more likely to participate in secondary sperm-ZP interactions following the induction of acrosomal exocytosis. Resolution of these contradictory data was recently afforded by the demonstration that $\mathrm{ZP} 3 \mathrm{R}$, in addition to other acrosomal matrix proteins, is progressively released to the sperm surface during capacitation. ${ }^{121,122}$ This dynamic change in localization suggests that part of the mechanism by which sperm attain their fully mature status involves the translocation of specific proteins from their initial acrosomal environment to regions of the plasma membrane capable of ZP interaction. Such a model challenges the widely held view of acrosomal exocytosis as an all or none reaction, and predicts that spermatozoa must have the potential to selectively traffic these proteins from the acrosome to the sperm surface. This would be both a unique and an intriguing mechanism that spermatozoa could employ to ensure that distinct receptor molecules are temporally presented to regulate their ability to bind the ZP.

Collectively, these data provide a strong argument against the traditional paradigm of sperm-ZP interaction being mediated by a solitary, constitutively expressed receptor. Indeed, on the basis of gene knockout studies, all of which have failed to induce the anticipated block to fertilization, ${ }^{113,123-125}$ it is considered very unlikely that a single receptor could be solely responsible for supporting this important binding event. Interest has instead turned to models that feature molecular redundancy in which sperm-ZP binding is achieved through the concerted action of a number of zona receptor molecules. An alternative explanation for the large number of potential zonabinding candidates is that each species utilize their own unique repertoire of $\mathrm{ZP}$ receptors. This argument, however, appears to be at odds with the relatively high degree of cross-species conversation recorded among the known sperm-ZP receptors. ${ }^{112,126-130}$ Nonetheless, recent data regarding the role of the sperm protein, zonadhesin, promises to improve our understanding of the mechanisms behind the speciesspecific nature of sperm-ZP binding. ${ }^{131}$ In this context, it has been shown that targeted deletion of zonadhesin leads to the production of mouse spermatozoa that bind promiscuously to the ZP of several divergent species. ${ }^{131}$

\section{FORMATION OF A MULTIMERIC ZONA RECOGNITION COMPLEX (MZRC)}

Given the complexity of the post-testicular maturation events that precede acquisition of the ability to adhere to the $\mathrm{ZP}$, it has recently been hypothesized that a cohort of sperm-based receptors may require active assembly and/or presentation in the form of a dynamic MZRC. ${ }^{132}$ This model of membrane priming draws interesting parallels with that of the early phases of membrane fusion that occur in many somatic cells.

\section{Membrane priming}

In a specialized cell, such as the spermatozoon, there are few intracellular domains, other than the acrosome, in which putative ZP receptors could be stored before surface presentation and assembly into an MZRC. The sperm acrosome is a sac-like vesicle that resides within the anterior aspect of the sperm head, positioned between the plasma membrane and the compact nucleus. This structure is enclosed within the inner acrosomal membrane and outer acrosomal membrane, which are located adjacent to the nucleus and sperm plasma membrane, respectively. ${ }^{133}$ In addition to the presence of numerous wellcharacterized hydrolytic enzymes (including hyaluronidase and acro$\sin$ ) that participate in digestion of the $\mathrm{ZP}$, the acrosome also contains a suite of glycoenzymes, the latter of which are a reflection of the fact that the organelle originates from the Golgi apparatus.

Interestingly, results of immunolocalization experiments on two such intra-acrosomal enzymes, $\beta$-D-galactosidase and $\beta$-D-glucuronidase, have highlighted that upon stimulation of capacitation in vitro, there is a time-dependent shift in their pattern of fluorescence. ${ }^{134}$ Specifically, their labeling changes from a thin, discrete lining to an intense spot-like pattern, the appearance of which may be because of contact between the outer acrosomal membrane and sperm plasma membrane, as capacitation progresses. This contact has been theorized to result from the binding of complementary SNARE proteins (soluble $\mathrm{N}$-ethylmaleimide-sensitive factor attachment protein receptor) and culminates in the production of fusion pores that provide a route for the presentation of the enzymes to the sperm surface. ${ }^{122}$ Such findings have since been extended to include a number of additional proteins such as arylsulfatase $\mathrm{A},{ }^{127,128,135}$ acrosin, ${ }^{136}$ hyaluronidase ${ }^{137}$ and ZP3R, ${ }^{119,138}$ each of which show a capacitation-dependent relocalization from the acrosome to the sperm surface. The translocation of these proteins may thus prime spermatozoa for subsequent binding to the ZP.

\section{Lipid rafts}

As mentioned previously, lipid rafts have been implicated in establishment of ZP recognition by spermatozoa owing to their function as stable platforms in which proteins important in sperm-ZP binding can aggregate. Despite their stability, ${ }^{139}$ lipid rafts remain highly dynamic and have been observed to display considerable lateral movement in various cell types as a response to physiological stimuli or cellular activation events. ${ }^{140}$ In sperm, lipid rafts have been identified by the presence of several somatic cell raft markers including 
$\mathrm{G}_{\mathrm{M} 1}$ gangliosides, flotillin and proteins that have 'raft' affinity owing to the presence of glycosylphosphatidylinositol anchors. A compelling functional link between lipid rafts, the construction of MZRCs and zona adhesion is supported by several lines of evidence. First, lipid rafts undergo an overt capacitation-associated reorganization from a uniform distribution to a pattern of confinement within the apical ridge of the sperm head, ${ }^{141-143}$ the precise region that mediates recognition and binding to the $\mathrm{ZP}$. Second, clusters containing zona-binding molecules and lipid raft markers comigrate in the plasma membrane of live spermatozoa after cholesterol reduction. ${ }^{144}$ Finally, lipid raft markers and zona-binding molecules partition into low-density detergent-resistant phases of the sperm plasma membrane $e^{145}$ and accordingly, these fractions display affinity for the ZP. ${ }^{145,146}$

\section{Molecular chaperones}

Though lipid rafts are proposed to function in the aggregation of specific receptor proteins, construction of a multimeric structure such as an MZRC would no doubt require more than just a simple aggregation of potential binding candidates. Consistent with this is evidence that a range of molecular chaperone proteins colocalize within lipid rafts. ${ }^{145}$ These molecular chaperones, or heat shock proteins (HSPs), have well-defined roles in the mediation of protein folding and trafficking, the assembly of multiprotein structures and the translocation of proteins across membranes. ${ }^{147,148}$ HSPs have been found to be induced in cells prone to elevations in temperature, physical or chemical stress, viral infection, drugs and transforming agents, where they exhibit a protective role through maintenance of protein homeostasis and blockade of caspase-dependent apoptosis. ${ }^{149,150}$ It should be noted, however, that whereas some members of the HSP family are only induced via stress, others are constitutively expressed and therefore are not susceptible to heat shock induction. The mammalian sperm surface has been demonstrated to express a number of HSP family members and a subset of these (HSP90B1, HSPA8 and HSPD1) has been detected within detergent resistant membranes. ${ }^{148,151,152}$ Not only do these HSPs localize to the same areas of the sperm plasma membrane as raft markers, but further evidence has indicated that HSP90B1 and HSPD1 also undergo capacitation-associated tyrosine phosphorylation, a modification necessary for their activation. ${ }^{153}$ These data support the model in which HSPs are involved in the conformational conversion and assembly of MZRCs at distinct locations on the sperm plasma membrane (that is, lipid rafts), and these regions correspond to those necessary for sperm-ZP interaction. Further work is, however, required to confirm the physical interaction between the HSPs and zona receptor proteins.

\section{CONCLUSION}

The three phases of sperm maturation, spermatogenesis, epididymal maturation and capacitation, greatly modify an inert, functionally incompetent cell into one that possesses fertilizing ability. Critical to the acquisition of this fertilizing ability is the substantial remodeling of the sperm plasma membrane that accompanies each of the stages. Capacitation-driven repositioning and selective aggregation of proteins believed to be important in sperm-ZP recognition are becoming increasingly well documented. It is also increasingly apparent that species-specific zona adhesion does not conform to a simple lock and key receptor-ligand interaction. On the contrary, the balance of evidence points toward models implicating multiple receptor molecules in sperm-ZP binding. The current suggestion is that aggregation of these receptor molecules at focal points on the sperm surface compatible with zona adhesion culminates in the assembly of an MZRC. Assembly of these MZRCs is believed to be effected through the action of molecular chaperones, which, together with their client proteins, are constricted to lipid rafts. The establishment of MZRCs may account for the elaborate level of modification necessary for production of functionally competent spermatozoa, and hence justify the enormous energy expenditure devoted to the sperm maturation process.

\section{COMPETING FINANCIAL INTERESTS}

The authors declare no competing financial interests.

1 Chen JS, Doncel GF, Alvarez C, Acosta AA. Expression of mannose-binding sites on human spermatozoa and their role in sperm-zona pellucida binding. J Androl 1995; 16: 55-63.

2 Chapman NR, Barratt CL. The role of carbohydrate in sperm-ZP3 adhesion. Mol Human Reprod 1996; 2: 767-74.

3 Miranda PV, Gonzalez-Echeverria F, Marin-Briggiler Cl, Brandelli A, Blaquier JA et al. Glycosidic residues involved in human sperm-zona pellucida binding in vitro. $\mathrm{Mol}$ Human Reprod 1997; 3: 399-404.

4 Gadella BM. The assembly of a zona pellucida binding protein complex in sperm. Reprod Domest Anim 2008; 43: 12-9.

5 Population Division. World population to exceed 9 billion by 2050. United Nations Department of Economic and Social Affairs: New York, USA, 2009.

6 Guttmacher Institute. Facts on induced abortion worldwide. World Health Organization: Geneva, Switzerland, 2007.

7 Bhasin S. Approach to the infertile man. J Clin Endocrinol Metab 2007; 92: 19952004.

8 Muratori M, Luconi M, Marchiani S, Forti G, Baldi E. Molecular markers of human sperm functions. Int J Androl 2008; 32: 25-45.

9 Hermo L, Pelletier RM, Cyr DG, Smith CE. Surfing the wave, cycle, life history, and genes/proteins expressed by testicular germ cells. Part 1: background to spermatogenesis, spermatogonia, and spermatocytes. Microsc Res Tech 2009; 73 : 241-78.

10 Hermo L, Pelletier RM, Cyr DG, Smith CE. Surfing the wave, cycle, life history, and genes/proteins expressed by testicular germ cells. Part 2: changes in spermatid organelles associated with development of spermatozoa. Microsc Res Tech 2009; 73: 279-319.

11 Hermo L, Pelletier RM, Cyr DG, Smith CE. Surfing the wave, cycle, life history, and genes/proteins expressed by testicular germ cells. Part 3: developmental changes in spermatid flagellum and cytoplasmic droplet and interaction of sperm with the zona pellucida and egg plasma membrane. Microsc Res Tech 2009; 73: 320-63.

12 Hermo L, Pelletier RM, Cyr DG, Smith CE. Surfing the wave, cycle, life history, and genes/proteins expressed by testicular germ cells. Part 4: intercellular bridges, mitochondria, nuclear envelope, apoptosis, ubiquitination, membrane/voltage-gated channels, methylation/acetylation, and transcription factors. Microsc Res Tech 2009; 73: 364-408.

13 Hermo L, Pelletier RM, Cyr DG, Smith CE. Surfing the wave, cycle, life history, and genes/proteins expressed by testicular germ cells. Part 5 : intercellular junctions and contacts between germs cells and Sertoli cells and their regulatory interactions, testicular cholesterol, and genes/proteins associated with more than one germ cell generation. Microsc Res Tech 2009; 73: 409-94.

14 Cornwall GA. New insights into epididymal biology and function. Hum Reprod Update 2009; 1: 1-15.

15 Bedford JM. Morphological changes in rabbit spermatozoa during passage through the epididymis. J Reprod Fertil 1963; 5: 169-77.

16 Bedford JM. Changes in fine structure of the rabbit sperm head during passage through the epididymis. J Anat 1965; 99: 891-906

17 Horan AH, Bedford JM. Development of the fertilizing ability of spermatozoa in the epididymis of the Syrian hamster. J Reprod Fertil 1972; 30: 417-23.

18 Saling PM. Development of the ability to bind to zonae pellucidae during epididymal maturation: reversible immobilization of mouse-spermatozoa by lanthanum. Biol Reprod 1982; 26: 429-36.

19 Cuasnicu PS, Gonzalez Echeverria F, Piazza A, Blaquier JA. Addition of androgens to cultured hamster epididymis increases zona recognition by immature spermatozoa. J Reprod Fertil 1984; 70: 541-7.

20 Fournier-Delpech S, Hamamah S, Tananis-Anthony C, Courot M, Orgebin-Crist M Hormonal regulation of zona-binding ability and fertilizing ability of rat epididymal spermatozoa. Gamete Res 1984; 9: 21-30.

21 Engel JC, Bernard EA, Wassermann GF. Protein synthesis by isolated spermatozoa from cauda and caput epididymis of rat. Acta Physiol Lat Am 1973; 23: 358-62.

22 Cooper TG. The Epididymis, Sperm Maturation and Fertilisation. Berlin: SpringerVerlag; 1986.

23 Jones R, James PS, Howes L, Bruckbauer A, Klenerman D. Supramolecular organization of the sperm plasma membrane during maturation and capacitation. Asian J Androl 2007; 9: 438-44. 
24 Nikolopoulou M, Soucek DA, Vary JC. Changes in the lipid content of boar sperm plasma membranes during epididymal maturation. Biochim Biophys Acta 1985; 815: 486-98.

25 Haidl G, Opper C. Changes in lipids and membrane anisotropy in human spermatozoa during epididymal maturation. Hum Reprod 1997; 12: 2720-3.

26 Aitken RJ, Nixon B, Lin M, Koppers AJ, Lee YH et al. Proteomic changes in mammalian spermatozoa during epididymal maturation. Asian J Androl 2007; 9: 554-64.

27 Legare C, Berube B, Boue F, Lefievre L, Morales CR et al. Hamster sperm antigen P26h is a phosphatidylinositol-anchored protein. Mol Reprod Dev 1999; 52: 225-33.

28 Rejraji H, Sion B, Prensier G, Carreras M, Motta C et al. Lipid remodeling of murine epididymosomes and spermatozoa during epididymal maturation. Biol Reprod 2006; 74: 1104-13.

29 Frenette G, Girouard J, Sullivan R. Comparison between epididymosomes collected in the intraluminal compartment of the bovine caput and cauda epididymidis. Biol Reprod 2006; 75: 885-90.

30 Asquith KL, Harman AJ, McLaughlin EA, Nixon B, Aitken RJ. Localization and significance of molecular chaperones, HSP1, and tumor rejection antigen gp96 in the male reproductive tract and during capacitation and acrosome reaction. Biol Reprod 2005; 72: 328-37

31 Griffiths GS, Galileo DS, Reese K, Martin-Deleon PA. Investigating the role of murine epididymosomes and uterosomes in GPI-linked protein transfer to sperm using SPAM 1 as a model. Mol Reprod Dev 2008; 75: 1627-36.

32 Yano R, Matsuyama T, Kaneko T, Kurio H, Murayama E et al. Bactericidal/ permeability-increasing protein is associated with the acrosome region of rodent epididymal spermatozoa. J Androl 2010; 31: 201-14.

33 Austin CR. Observations on the penetration of the sperm in the mammalian egg. Aust J Sci Res B 1951; 4: 581-96.

34 Chang MC. Fertilizing capacity of spermatozoa deposited into the fallopian tubes. Nature 1951; 168: 697-8.

35 Austin CR. The 'capacitation' of the mammalian sperm. Nature 1952; 170: 326.

36 Aitken RJ, Harkiss D, Knox W, Paterson M, Irvine DS. A novel signal transduction cascade in capacitating human spermatozoa characterised by a redox-regulated, cAMP-mediated induction of tyrosine phosphorylation. J Cell Sci 1998; 111: 645-56.

37 Baldi E, Luconi M, Bonaccorsi L, Muratori M, Forti G. Intracellular events and signaling pathways involved in sperm acquisition of fertilizing capacity and acrosome reaction. Front Biosci 2000; 5: E110-23.

38 Visconti PE, Bailey JL, Moore GD, Pan D, Olds-Clarke P et al. Capacitation of mouse spermatozoa. I. Correlation between the capacitation state and protein tyrosine phosphorylation. Development 1995; 121: 1129-37.

39 Nixon B, Aitken RJ, McLaughlin EA. New insights into the molecular mechanisms of sperm-egg interaction. Cell Mol Life Sci 2007; 64: 1805-23.

40 Davis B. Timing of fertilization in mammals: sperm cholesterol/phospholipid ratio as a determinant of the capacitation interval. Proc NatI Acad Sci USA 1981; 78: 7560-4.

41 Visconti PE, Ning X, Fornes MW, Alvarez JG, Stein P et al. Cholesterol efflux-mediated signal transduction in mammalian sperm: cholesterol release signals an increase in protein tyrosine phosphorylation during mouse sperm capacitation. Dev Biol 1999; 214: 429-43.

42 Langlais J, Kan FW, Granger L, Raymond L, Bleau G et al. Identification of sterol acceptors that stimulate cholesterol efflux from human spermatozoa during in vitro capacitation. Gamete Res 1988; 20: 185-201.

43 Davis B, Byrne R, Hungund B. Studies on the mechanism of capacitation II. Evidence for lipid transfer between plasma membrane of rat sperm and serum albumin during capacitation in vitro. Biochim Biophys Acta 1979; 558: 257-66.

44 Martínez P. Morros A. Membrane lipid dynamics during human sperm capacitation. Front Biosci 1996; 1: d103-17.

45 Okamura N, Tajima Y, Soejima A, Masuda H, Sugita Y. Sodium bicarbonate in seminal plasma stimulates the motility of mammalian spermatozoa through direct activation of adenylate cyclase. J Biol Chem 1985; 260: 9699-705.

46 Boatman DE, Robbins RS. Bicarbonate: carbon-dioxide regulation of sperm capacitation, hyperactivated motility, and acrosome reactions. Biol Reprod 1991; 44: 806-13.

47 Garty NB, Salomon Y. Stimulation of partially purified adenylate cyclase from bull sperm by bicarbonate. FEBS Lett 1987; 218: 148-52.

48 Chen Y, Cann MJ, Litvin TN, lourgenko V, Sinclair ML et al. Soluble adenylyl cyclase as an evolutionarily conserved bicarbonate sensor. Science 2000; 289: 625-8.

49 Gadella BM, Harrison RA. The capacitating agent bicarbonate induces protein kinase A-dependent changes in phospholipid transbilayer behavior in the sperm plasma membrane. Development 2000; 127: 2407-20.

50 Gadella BM, Harrison RA. Capacitation induces cyclic adenosine 3', 5'monophosphate-dependent, but apoptosis-unrelated, exposure of aminophospholipids at the apical head plasma membrane of boar sperm cells. Biol Reprod 2002; 67: 34050.

51 Flesch FM, Brouwers JF, Nievelstein PF, Verkleij AJ, van Golde LM et al. Bicarbonate stimulated phospholipid scrambling induces cholesterol redistribution and enables cholesterol depletion in the sperm plasma membrane. J Cell Sci 2001; 114: 354355.

52 Harrison AP. Bicarbonate-induced membrane processing in sperm capacitation. Theriogenology 2005; 63: 342-51.

53 Fraser LR. Mouse sperm capacitation in vitro involves loss of a surface-associated inhibitory component. J Reprod Fertil 1984; 72: 373-84.

54 Ni Y, Zhou Y, Chen WY, Zheng M, Yu J et al. HongrES1, a cauda epididymis-specific protein, is involved in capacitation of guinea pig sperm. Mol Reprod Dev 2009; 76: 984-93
55 Fraser LR. Interactions between a decapacitation factor and mouse spermatozoa appear to involve fucose residues and a GPI-anchored receptor. Mol Reprod Dev 1998; 51: 193-202.

56 Gibbons R, Adeoya-Osiguwa SA, Fraser LR. A mouse sperm decapacitation factor receptor is phosphatidylethanolamine-binding protein 1 . Reproduction 2005; 130 : 497-508.

57 Bi Y, Xu WM, Wong HY, Zhu H, Zhou ZM et al. NYD-SP27, a novel intrinsic decapacitation factor in sperm. Asian J Androl 2009; 11: 229-39.

58 Pike LJ. Rafts defined: a report on the keystone symposium on lipid rafts and cell function. J Lipid Res 2006; 47: 1597-8.

59 Simons K, Ikonen E. Functional rafts in cell membranes. Nature 1997; 387: 569-72.

60 Simons K, Toomre D. Lipid rafts and signal transduction. Nat Rev Mol Cell Biol2000; 1: 31-9.

61 Brown DA, London E. Functions of lipid rafts in biological membranes. Annu Rev Cell Dev Biol 1998; 14: 111-36.

62 Brown DA, London E. Structure and function of sphingolipid- and cholesterol-rich membrane rafts. J Biol Chem 2000; 275: 17221-4.

63 Schuck S, Honsho M, Ekroos K, Shevchenko A, Simons K. Resistance of cell membranes to different detergents. Proc Natl Acad Sci USA 2003; 100: 5795-800.

64 Wassarman PM. Regulation of mammalian fertilization by zona pellucida glycoproteins. J Reprod Fertil Supp/ 1990; 42: 79-87.

65 Yanagimachi R. Fertility of mammalian spermatozoa: its development and relativity. Zygote 1994; 2: 371-2

66 Wassarman PM, Litscher ES. Mammalian fertilization: the egg's multifunctional zona pellucida. Int J Dev Biol 2008; 52: 665-76.

67 Sinowatz F, Topfer-Petersen E, Kolle S, Palma G. Functional morphology of the zona pellucida. Anat Histol Embryol 2001; 30: 257-63.

68 Bauskin AR, Franken DR, Eberspaecher U, Donner P. Characterization of human zona pellucida glycoproteins. Mol Human Reprod 1999; 5: 534-40.

69 Lefievre L, Conner SJ, Salpekar A, Olufowobi O, Ashton P et al. Four zona pellucida glycoproteins are expressed in the human. Hum Reprod 2004; 19: 1580-6.

70 Goudet G, Mugnier S, Callebaut I, Monget P. Phylogenetic analysis and identification of pseudogenes reveal a progressive loss of zona pellucida genes during evolution of vertebrates. Biol Reprod 2008; 78: 796-806.

71 Greve J, Wassarman P. Mouse egg extracellular coat is a matrix of interconnected filaments possessing a structural repeat. J Mol Biol 1985; 181: 253-64.

72 Wassarman P, Mortillo S. Structure of the mouse egg extracellular coat, the zona pellucida. Int Rev Cytol 1991: 85-109.

73 Aitken R. The complexities of conception. Science 1995; 269: 39-40.

74 Bleil JD, Wassarman PM. Mammalian sperm-egg interaction: identification of a glycoprotein in mouse egg zonae pellucidae possessing receptor activity for sperm. Cell 1980; 20: 873-82.

75 Bleil J, Wassarman P. Structure and function of the zona pellucida: identification and characterization of the proteins of the mouse oocyte's zona pellucida. Dev Biol 1980; 76: 185-202

76 Vazquez M, Phillips D, Wassarman P. Interaction of mouse sperm with purified sperm receptors covalently linked to silica beads. J Cell Sci 1989; 92: 713-22.

77 Florman H, Bechtol K, Wassarman P. Enzymatic dissection of the functions of the mouse egg's receptor for sperm. Dev Biol 1984; 106: 243-55

78 Mortillo S, Wassarman P. Differential binding of gold-labeled zona pellucida glycoproteins mZP2 and mZP3 to mouse sperm membrane compartments. Development 1991; 113: 141

79 Liu C, Litscher ES, Mortillo S, Sakai Y, Kinloch RA et al. Targeted disruption of the $m Z P 3$ gene results in production of eggs lacking a zona pellucida and infertility in female mice. Proc Natl Acad Sci USA 1996: 93: 5431-6.

80 Gwatkin R, Williams D. Receptor activity of the hamster and mouse solubilized zona pellucida before and after the zona reaction. Reproduction 1977; 49: 55-9.

81 Hoodbhoy T, Dean J. Insights into the molecular basis of sperm-egg recognition in mammals. Reproduction 2004; 127: 417-22.

82 Oikawa T, Nicolson G, Yanagimachi R. Inhibition of hamster fertilization by phytoagglutinins. Exp Cell Res 1974; 83: 239-46.

83 Mori K, Daitoh T, Irahara M, Kamada M, Aono T. Significance of D-mannose as a sperm receptor site on the zona pellucida in human fertilization. Am J Obstet Gynecol 1989; 161: 207-11

84 Huang TT, Ohzu E, Yanagimachi R. Evidence suggesting that L-fucose is part of a recognition signal for sperm-zona pellucida attachment in mammals. Gamete Res 1982; 5: 355-61.

85 Shur BD, Hall NG. A role for mouse sperm surface galactosyltransferase in sperm binding to the egg zona pellucida. J Cell Biol 1982; 95: 574-9.

86 Shalgi R, Matityahu A, Nebel L. The role of carbohydrates in sperm-egg interaction in rats. Biol Reprod 1986; 34: 446-52.

87 Oehninger S, Acosta A, Hodgen G. Antagonistic and agonistic properties of saccharide moieties in the hemizona assay. Fertil Steril 1990; 53: 143.

88 Ahuja K, Gilburt D. Involvement of sperm sulphatases in early sperm-zona interactions in the hamster. J Cell Sci 1985; 78: 247-61.

89 Oehninger S, Clark GF, Acosta AA, Hodgen GD. Nature of the inhibitory effect of complex saccharide moieties on the tight binding of human spermatozoa to the human zona pellucida. Fertil Steril 1991; 55: 165-9.

90 Chen J, Litscher ES, Wassarman PM. Inactivation of the mouse sperm receptor, mZP3, by site-directed mutagenesis of individual serine residues located at the combining site for sperm. Proc Natl Acad Sci USA 1998; 95: 6193-7.

91 Florman HM, Wassarman PM. O-linked oligosaccharides of mouse egg ZP3 account for its sperm receptor activity. Cell 1985; 41: 313-24. 
92 Litscher ES, Wassarman PM. Characterization of a mouse ZP3-derived glycopeptide, gp55, that exhibits sperm receptor and acrosome reaction-inducing activity in vitro. Biochemistry 1996; 35: 3980-5.

93 Litscher ES, Juntunen K, Seppo A, Penttila L, Niemela R et al. Oligosaccharide constructs with defined structures that inhibit binding of mouse sperm to unfertilized eggs in vitro. Biochemistry (Mosc) 1995; 34: 4662-9.

94 Rosiere $T$, Wassarman $P$. Identification of a region of mouse zona pellucida glycoprotein mZP3 that possesses sperm receptor activity. Dev Biol 1992; 154 309-17.

95 Easton RL, Patankar MS, Lattanzio FA, Leaven TH, Morris HR et al. Structural analysis of murine zona pellucida glycans. J Biol Chem 2000; 275: 7731-42.

96 Ellies LG, Tsuboi S, Petryniak B, Lowe JB, Fukuda M et al. Core 2 oligosaccharide biosynthesis distinguishes between selectin ligands essential for leukocyte homing and inflammation. Immunity 1998; 9: 881-90.

97 Stone EL, Ismail MN, Lee SH, Luu Y, Ramirez K et al. Glycosyltransferase function in core 2-type protein O glycosylation. Mol Cell Biol 2009; 29: 3770-82.

98 Shi S, Williams SA, Seppo A, Kurniawan $\mathrm{H}$, Chen W et al. Inactivation of the Mgat 1 gene in oocytes impairs oogenesis, but embryos lacking complex and hybrid $\mathrm{N}$-glycans develop and implant. Mol Cell Biol 2004; 24: 9920-9.

99 Yonezawa N, Aoki H, Hatanaka Y, Nakano M. Involvement of $\mathrm{N}$-linked carbohydrate chains of pig zona pellucida in sperm-egg binding. Eur J Biochem 1995; 233: 35-41.

100 Nakano M, Yonezawa N, Hatanaka Y, Noguchi S. Structure and function of the $N$ linked carbohydrate chains of pig zona pellucida glycoproteins. J Reprod Fertil Supp/ 1996; 50: 25-34.

101 Chiu PC, Wong BS, Chung MK, Lam KK, Pang RT et al. Effects of native human zona pellucida glycoproteins 3 and 4 on acrosome reaction and zona pellucida binding of human spermatozoa. Biol Reprod 2008; 79: 869-77.

102 Chapman N, Kessopoulou E, Andrews P, Hornby D, Barratt CR. The polypeptide backbone of recombinant human zona pellucida glycoprotein-3 initiates acrosomal exocytosis in human spermatozoa in vitro. Biochem J 1998; 330 (Pt 2): 839-45.

103 Hinsch E, Aires VA, Hedrich F, Oehninger S, Hinsch KD. A synthetic decapeptide from a conserved ZP3 protein domain induces the $G$ protein-regulated acrosome reaction in bovine spermatozoa. Theriogenology 2005; 63: 1682-94.

104 Dean J. Reassessing the molecular biology of sperm-egg recognition with mouse genetics. Bioessays 2004; 26: 29-38.

105 Dean J. Molecular biology of sperm-egg interactions. Andrologia 2005; 37: 198-9.

106 Rodeheffer C, Shur BD. Characterization of a novel ZP3-independent sperm-binding ligand that facilitates sperm adhesion to the egg coat. Development 2004; 131: 503 12.

107 Lyng R, Shur BD. Mouse oviduct-specific glycoprotein is an egg-associated ZP3independent sperm-adhesion ligand. J Cell Sci 2009; 122: 3894-906.

108 Miller DJ, Macek MB, Shur BD. Complementarity between sperm surface beta-1,4 galactosyltransferase and egg-coat ZP3 mediates sperm-egg binding. Nature 1992; 357: 589-93.

109 Shur BD, Neely CA. Plasma membrane association, purification, and partial characterization of mouse sperm beta 1,4-galactosyltransferase. J Biol Chem 1988; 263: 17706-14.

110 Gong X, Dubois DH, Miller DJ, Shur BD. Activation of a G protein complex by aggregation of beta-1,4-galactosyltransferase on the surface of sperm. Science 1995; 269: 1718-21.

111 Chiu PC, Chung MK, Koistinen R, Koistinen H, Seppala M et al. Glycodelin-A interacts with fucosyltransferase on human sperm plasma membrane to inhibit spermatozoazona pellucida binding. J Cell Sci 2007; 120: 33-44.

112 Cornwall G, Tulsiani D, Orgebin-Crist M. Inhibition of the mouse sperm surface alphaD-mannosidase inhibits sperm-egg binding in vitro. Biol Reprod 1991; 44: 913-21.

$113 \mathrm{Lu}$ Q, Shur BD. Sperm from beta 1,4-galactosyltransferase-null mice are refractory to ZP3-induced acrosome reactions and penetrate the zona pellucida poorly. Development 1997; 124: 4121-31.

114 O'Rand MG, Widgren EE, Fisher SJ. Characterization of the rabbit sperm membrane autoantigen, RSA, as a lectin-like zona binding protein. Dev Biol 1988; 129: 231-40.

115 Bleil JD, Wassarman PM. Identification of a ZP3-binding protein on acrosomeintact mouse sperm by photoaffinity crosslinking. Proc Natl Acad Sci USA 1990; 87: 5563-7.

116 Bleil J, Wassarman P. Galactose at the nonreducing terminus of 0 -linked oligosaccharides of mouse egg zona pellucida glycoprotein ZP3 is essential for the glycoprotein's sperm receptor activity. Proc Natl Acad Sci USA 1988; 85: 6778-82.

117 Buffone MG, Zhuang T, Ord TS, Hui L, Moss SB et al. Recombinant mouse sperm ZP3binding protein (ZP3R/sp56) forms a high order oligomer that binds eggs and inhibits mouse fertilization in vitro. J Biol Chem 2008; 283: 12438-45.

118 Cheng A, Le T, Palacios M, Bookbinder LH, Wassarman PM et al. Sperm-egg recognition in the mouse: characterization of $\mathrm{sp} 56$, a sperm protein having specific affinity for ZP3. J Cell Biol 1994; 125: 867-78.

$119 \mathrm{Kim}$ KS, Cha MC, Gerton GL. Mouse sperm protein sp56 is a component of the acrosomal matrix. Biol Reprod 2001; 64: 36-43.

120 Foster JA, Friday BB, Maulit MT, Blobel C, Winfrey VP et al. AM67, a secretory component of the guinea pig sperm acrosomal matrix, is related to mouse sperm protein sp56 and the complement component 4-binding proteins. $\mathrm{J}$ Biol Chem 1997; 272: 12714-22.

121 Kim KS, Gerton GL. Differential release of soluble and matrix components: evidence for intermediate states of secretion during spontaneous acrosomal exocytosis in mouse sperm. Dev Biol 2003; 264: 141-52.
122 Tulsiani DRP, Abou-Haila A. Is sperm capacitation analogous to early phases of $\mathrm{Ca}^{2+}$ triggered membrane fusion in somatic cells and viruses? Bioessays 2004; 26: 281-90.

123 Inoue N, Ikawa M, Nakanishi T, Matsumoto M, Nomura M et al. Disruption of mouse CD46 causes an accelerated spontaneous acrosome reaction in sperm. $\mathrm{Mol}$ Cell Biol 2003; 23: 2614-22.

124 Cho C, O'Dell Bunch D, Faure JE, Goulding EH, Eddy EM et al. Fertilization defects in sperm from mice lacking fertilin beta. Science 1998; 281: 1857-9.

125 Ensslin MA, Shur BD. Identification of mouse sperm SED1, a bimotif EGF repeat and discoidin-domain protein involved in sperm-egg binding. Cell 2003; 114: 405-17.

126 Rattanachaiyanont M, Weerachatyanukul W, Leveille MC, Taylor T, D'Amours D et al. Anti-SLIP1-reactive proteins exist on human spermatozoa and are involved in zona pellucida binding. Mol Hum Reprod 2001; 7: 633-40.

127 Carmona E, Weerachatyanukul W, Soboloff T, Fluharty A, White D et al. Arylsulfatase A is present on the pig sperm surface and is involved in sperm-zona pellucida binding. Dev Biol 2002; 247: 182-96.

128 Tantibhedhyangkul J, Weerachatyanukul W, Carmona E, Xu H, Anupriwan A et al. Role of sperm surface arylsulfatase A in mouse sperm-zona pellucida binding. Biol Reprod 2002; 67: 212.

129 Tulsiani D, Skudlarek M, Orgebin-Crist M. Novel alpha-D-mannosidase of rat sperm plasma membranes: characterization and potential role in sperm-egg interactions. J Cell Biol 1989; 109: 1257-67.

130 Tulsiani D, Skudlarek M, Orgebin-Crist M. Human sperm plasma membranes possess al pha-D-mannosidase activity but no galactosyltransferase activity. Biol Reprod 1990; 42: 843-58

131 Tardif S, Wilson MD, Wagner R, Hunt P, Gertsenstein M et al. Zonadhesin is essential for species specificity of sperm adhesion to the egg's zona pellucida. $J$ Biol Chem 2010; 285: 24863-70.

132 Nixon $\mathrm{B}$, Asquith $\mathrm{KL}$, John Aitken $\mathrm{R}$. The role of molecular chaperones in mouse sperm-egg interactions. Mol Cell Endocrinol 2005; 240: 1-10.

133 Abou-Haila A, Tulsiani DR. Mammalian sperm acrosome: formation, contents, and function. Arch Biochem Biophys 2000; 379: 173-82.

134 Abou-Haila A, Tulsiani DR. Evidence for the capacitation-associated membrane priming of mouse spermatozoa. Histochem Cell Biol 2003; 119: 179-87.

135 Yang $\mathrm{CH}$, Srivastava PN, Williams WL. Purification and properties of aryl sulfatases from rabbit sperm acrosomes. Proc Soc Exp Biol Med 1974; 145: 721-5.

136 Tesarik J, Drahorad J, Testart J, Mendoza C. Acrosin activation follows its surface exposure and precedes membrane fusion in human sperm acrosome reaction. Development 1990; 110: 391-400.

137 Meyers SA, Rosenberger AE. A plasma membrane-associated hyaluronidase is localized to the posterior acrosomal region of stallion sperm and is associated with spermatozoal function. Biol Reprod 1999; 61: 444-51.

$138 \mathrm{Kim}$ KS, Foster JA, Gerton GL. Differential release of guinea pig sperm acrosomal components during exocytosis. Biol Reprod 2001; 64: 148-56.

139 Nixon B, Aitken RJ. The biological significance of detergent-resistant membranes in spermatozoa. J Reprod Immunol 2009; 83: 8-13.

140 Simons K, Vaz WLC. Model systems, lipid rafts, and cell membranes. Annu Rev Biophys Biomol Struct 2004; 33: 269-95.

141 Shadan S, James PS, Howes EA, Jones R. Cholesterol efflux alters lipid raft stability and distribution during capacitation of boar spermatozoa. Biol Reprod 2004; 71: 253-65.

142 Gibbs GM, Lo JC, Nixon B, Jamsai D, O'Connor AE et al. Glioma pathogenesis-related 1 -like 1 is testis enriched, dynamically modified, and redistributed during male germ cell maturation and has a potential role in sperm-oocyte binding. Endocrinology 2010; 151: 2331-42.

143 van Gestel RA, Brewis IA, Ashton PR, Helms JB, Brouwers JF et al. Capacitationdependent concentration of lipid rafts in the apical ridge head area of porcine sperm cells. Mol Hum Reprod 2005; 11: 583-90.

144 Jones R, Howes E, Dunne PD, James P, Bruckbauer A et al. Tracking diffusion of GM1 gangliosides and zona pellucida binding molecules in sperm plasma membranes following cholesterol efflux. Dev Biol 2010; 339: 398-406.

145 Nixon B, Bielanowicz A, McLaughlin EA, Tanphaichitr N, Ensslin MA et al. Composition and significance of detergent resistant membranes in mouse spermatozoa. J Cell Physiol 2009; 218: 122-34.

146 Khalil MB, Chakrabandhu K, Xu H, Weerachatyanukul W, Buhr M et al. Sperm capacitation induces an increase in lipid rafts having zona pellucida binding ability and containing sulfogalactosylglycerolipid. Dev Biol 2006; 290: 220-35.

147 Bukau B, Weissman J, Horwich A. Molecular chaperones and protein quality control. Cell 2006; 125: 443-51.

148 Naaby-Hansen S, Herr JC. Heat shock proteins on the human sperm surface. J Reprod Immunol 2010; 84: 32-40.

149 Santoro MG, Amici C, Rossi A. Role of heat shock proteins in viral infection. In: Pockley AG, Calderwood SK, Santoro MG, editors. Prokaryotic and Eukaryotic Heat Shock Proteins in Infectious Disease. Dordrecht: Springer; 2010. pp51-84.

150 Joly AL, Wettstein G, Mignot G, Ghiringhelli F, Garrido C. Dual role of heat shock proteins as regulators of apoptosis and innate immunity. J Innate Immun 2010; 2 238-47.

151 Miller D, Brough S, Al-Harbi O. Characterization and cellular distribution of human spermatozoal heat shock proteins. Hum Reprod 1992; 7: 637-45.

152 Walsh A, Whelan D, Bielanowicz A, Skinner B, Aitken RJ et al. Identification of the molecular chaperone, heat shock protein 1 (chaperonin 10), in the reproductive tract and in capacitating spermatozoa in the male mouse. Biol Reprod 2008; 78: 983-93.

153 Asquith KL, Baleato RM, McLaughlin EA, Nixon B, Aitken RJ. Tyrosine phosphorylation activates surface chaperones facilitating sperm-zona recognition. J Cell Sci 2004; 117: 3645-57. 
154 Fraser LR, Harrison RAP, Herod JE. Characterization of a decapacitation factor associated with epididymal mouse spermatozoa. Reproduction 1990; 89: 135-48.

155 Adeoya-Osiguwa SA, Fraser LR. Evidence for $\mathrm{Ca}^{2+}$-dependent ATPase activity, stimulated by decapacitation factor and calmodulin, in mouse sperm. Mol Reprod Dev 1996; 44: 111-20.

156 Visconti PE, Galantino-Homer H, Ning X, Moore GD, Valenzuela JP et al. Cholesterol efflux-mediated signal transduction in mammalian sperm. Beta-cyclodextrins initiate transmembrane signaling leading to an increase in protein tyrosine phosphorylation and capacitation. J Biol Chem 1999; 274: 3235-42.

157 de Vries KJ, Wiedmer T, Sims PJ, Gadella BM. Caspase-independent exposure of aminophospholipids and tyrosine phosphorylation in bicarbonate responsive human sperm cells. Biol Reprod 2003; 68: 2122-34.
158 Visconti PE. Understanding the molecular basis of sperm capacitation through kinase design. Proc Natl Acad Sci USA 2009; 106: 667-8.

159 Visconti PE, Moore GD, Bailey JL, Leclerc P, Connors SA et al. Capacitation of mouse spermatozoa. II. Protein tyrosine phosphorylation and capacitation are regulated by a cAMP-dependent pathway. Development 1995; 121: 1139-50.

160 Nixon B, Bielanowicz A, Anderson AL, Walsh A, Hall T et al. Elucidation of the signaling pathways that underpin capacitation-associated surface phosphotyrosine expression in mouse spermatozoa. J Cell Physiol 2010; 224: 71-83.

161 Baibakov B, Gauthier L, Talbot P, Rankin TL, Dean J. Sperm binding to the zona pellucida is not sufficient to induce acrosome exocytosis. Development 2007; 134: 933.

162 Mayorga LS, Tomes CN, Belmonte SA. Acrosomal exocytosis, a special type of regulated secretion. IUBMB life 2007; 59: 286-92. 